\title{
AVALIAÇÃO DOS PROCESSOS DE PRECIPITAÇÃO QUÍMICA DE EFLUENTE GALVÂNICO COM HIDRÓXIDO DE CÁLCIO E CARBONATO DE SÓDIO
}

\author{
S. J. B. PERINI ${ }^{1}$, H. C. M, SOUZA ${ }^{2}$, M. L. MOLIN ${ }^{3}$, B. L. B. PERINI ${ }^{4}$, N. SELLIN ${ }^{5}$ \\ ${ }^{1,4,5}$ Universidade da Região de Joinville, Mestrado em Engenharia de Processos \\ ${ }^{2}$ Universidade da Região de Joinville, Departamento de Engenharia Ambiental e Sanitária \\ ${ }^{3}$ Universidade da Região de Joinville, Departamento de Engenharia Química \\ e-mail: nsellin@yahoo.com.br
}

\begin{abstract}
RESUMO - Neste trabalho, a substituição do agente precipitante hidróxido de cálcio por carbonato de sódio no tratamento físico-químico de efluente galvânico, visando reaproveitamento do lodo gerado foi avaliada. Os ensaios foram realizados em Teste de Jarros, a partir dos quais foram definidas as melhores condições experimentais, que resultaram em menor volume de lodo formado e em baixas concentrações dos metais dissolvidos no sobrenadante em níveis recomendados pela legislação ambiental vigente para lançamento de efluente. As eficiências de remoção dos contaminantes e de geração de lodo empregando os dois métodos foram determinadas e comparadas. Os resultados indicaram que a eficiência de remoção dos metais ferro e zinco variaram de $91,2 \%$ a $99,5 \%$. As maiores eficiências foram observadas para a precipitação química em $\mathrm{pH}$ 9. Para ajustar o $\mathrm{pH}$, foram usadas maiores quantidades de soda barrilha do que cal hidratada. Houve maior geração de lodo empregando a cal hidratada.
\end{abstract}

\section{INTRODUÇÃO}

A galvanoplastia é um processo químico ou eletroquímico de deposição de uma fina camada de um metal sobre uma superfície, que pode ser metálica ou não. Este processo usa a corrente elétrica, sendo chamado de "eletrólise". A finalidade deste processo é proteger as peças contras às intempéries e ao manuseio, melhorar a condutividade, aliviar tensões em determinadas peças, aumentar a durabilidade, a maleabilidade, a resistência ao calor e a capacidade de estampagem, melhorar a capacitação para soldar sobre a superfície tratada, além de tratamento estético e melhoria da dureza superficial (Vaz, 2009).

Os principais tratamentos de galvanização são: por eletrodeposição ou galvanoplastia, por imersão a quente e a fosfatização (Valenzuela, 1999; Queiroz, 2003). De modo geral, o processamento industrial em galvânicas pode ser considerado como tendo duas atividades básicas, que consistem na limpeza da peça (preparação da sua superfície para recebimento da camada de revestimento) e a aplicação da camada metálica propriamente dita.

Normalmente, os efluentes gerados em operações de galvanoplastia consistem nos descartes periódicos dos diversos banhos concentrados exauridos (desengraxantes, decapantes, fosfatizantes, banhos de eletrodeposição, etc.). Após cada etapa do processo 
galvânico, as peças são lavadas diversas vezes via imersão das mesmas em banhos de enxágue. Dessas etapas provém o maior volume de efluentes contendo metais pesados, que deve ser submetido a tratamento prévio ao seu descarte. Além disso, os efluentes são geralmente coloridos, alguns com temperatura superior a ambiente, emitem vapores tóxicos e apresentam pH's que atingem os extremos ácidos ou alcalinos (Pereira Neto et al., 2008; Silva et al., 2007). Tratar os efluentes gerados nos diversos tipos de empresas da área de tratamento de superfície é, portanto, extremamente necessário e indispensável, independente do volume de descarte (Nascimento, 2012; Toze, 2005).

Normalmente, o tratamento de efluentes galvânicos é realizado por processos físicoquímicos. Dentre as diversas formas disponíveis de tratamento, destaca-se a precipitação química seguida de coagulação e floculação e decantação, para a remoção dos metais dissolvidos nos efluentes líquidos. Este processo transforma pequenas partículas em agregados maiores (lodo) passíveis de sedimentação (Vaz, 2009; Colares et al., 2010). Uma grande quantidade de lodo é gerada nesse processo e é classificado como resíduo perigoso, de acordo com a NBR 10.004 (ABNT, 2004).

A maioria das indústrias de galvanização utiliza hidróxido de cálcio $\left[\mathrm{Ca}(\mathrm{OH})_{2}\right]$ como agente precipitante para remoção dos metais dissolvidos no efluente e completa o tratamento por meio de coagulação/floculação e decantação (Braile e Cavalcanti, 1993). Tal precipitante origina grande quantidade de lodo galvânico composto essencialmente de hidróxidos dos metais pesados, os quais não são potencialmente reaproveitados. Visando o aproveitamento de lodo gerado, neste trabalho, avaliou-se a substituição do hidróxido de cálcio por carbonato de sódio $\left(\mathrm{Na}_{2} \mathrm{CO}_{3}\right)$ no tratamento de efluente galvânico.

\section{METODOLOGIA}

\subsection{Amostragem e caracterização do efluente galvânico}

As amostras de efluente bruto foram coletadas, em diferentes dias e horários, na entrada do tanque de equalização da ETE de uma empresa galvânica e submetidas às análises físico-químicas para determinação dos parâmetros $\mathrm{pH}$, cor, turbidez, condutividade, ferro e zinco. A análise de turbidez foi realizada em turbidímetro $2100 \mathrm{Hach}$; a cor aparente por colorímetro Aquacolor Policontrol, e DQO e metais pesados em Espectrofotômetro HACH, de acordo com o Standard Methods for the Examination of Water and Wastewater (APHA, 2005).

Após avaliação destes parâmetros, o efluente foi submetido aos ensaios de tratamento por precipitação química empregando hidróxido de cálcio (cal hidratada) e carbonato de sódio (soda barrrilha), seguido de floculação com polímero aniônico, decantação e filtração para separação e quantificação do lodo gerado.

\subsection{Tratamento do efluente galvânico por precipitação química}

Os ensaios de precipitação química foram realizados em Teste de Jarros. Foram adicionadas quantidades de suspensão de cal e solução de soda barrilha, ambas com concentração de $50 \mathrm{mg} / \mathrm{L}$, nas amostras de efluente até elevar o pH para 8 e 9 . A adição dos agentes precipitantes foi efetuada sob agitação constante de $100 \mathrm{rpm}$, durante $1 \mathrm{~min}$. Após isso, a solução de polímero aniônico, nas concentrações de 10,15 e $20 \mathrm{mg} / \mathrm{L}$, foi adicionada 
nas amostras precipitadas com cal hidratada e soda barrilha nos dois diferentes pH's e a agitação foi reduzida para $30 \mathrm{rpm}$ e mantida constante por $1 \mathrm{~min}$. Após a floculação, foi desligado o sistema de agitação e deixado o efluente decantar por $10 \mathrm{~min}$. O lodo gerado foi separado do efluente decantado por filtração a vácuo, empregando papel filtro previamente pesado. Após filtração, o papel filtro contendo o lodo foi seco em estufa a $60{ }^{\circ} \mathrm{C}$ por 24 horas e pesado novamente, e o teor de lodo gerado foi quantificado por diferença de massa antes e após a secagem.

\subsection{Caracterização do efluente tratado e eficiência do tratamento}

As amostras de efluente tratado foram caracterizadas com relação aos teores de ferro e zinco, os quais foram determinados seguindo os mesmos procedimentos empregados para o efluente bruto. A eficiência do tratamento na remoção desses metais foi determinada, como segue:

$$
\text { \% eficiência }=\left[\left(\text { Parâmetro }_{\text {Efl. bruto }}-\text { Parâmetro }_{\text {Efl. tratado }}\right) / \text { Parâmetro }_{\text {Efl. bruto }}\right] \times 100
$$

\section{RESULTADOS E DISCUSSÃO}

\subsection{Parâmetros físico-químicos do efluente bruto}

Na Tabela 1 estão apresentados os resultados preliminares dos parâmetros físicoquímicos determinados para as amostras de efluente bruto. As amostras com $\mathrm{pH}$ acima de 7 não foram caracterizadas com relação aos parâmetros zinco e ferro e nem submetidas aos ensaios de precipitação, pois já estavam com pH acima da faixa de precipitação química dos metais como zinco e ferro, entre 8 e 9, e também, porque teria que adicionar ácido para abaixar o $\mathrm{pH}$ e depois adicionar os agentes precipitantes para elevar o mesmo, aumentando o consumo de reagentes químicos no tratamento. Na ETE, isto pode ser minimizado pela adição de efluente ácido oriundo da etapa de decapagem ácida.

Observa-se dos valores apresentados na Tabela 1 que há grande variação nos parâmetros analisados mesmo para as amostras coletadas num mesmo dia, em diferentes horários. Este comportamento pode ser explicado em função da empresa galvânica realizar o tratamento superficial de diferentes tipos de peças e em diferentes quantidades, levando à geração de efluente com diferentes características e que são encaminhados à ETE.

Algumas amostras apresentaram $\mathrm{pH}$ elevado, acima de 10, o que ocorreu provavelmente devido ao descarte para a ETE de quantidade significativa do efluente do banho de desengraxante alcalino em relação ao descarte de efluente da decapagem ácida, no período em que a coleta das amostras foi realizada. As amostras de efluente apresentaram teores de zinco significativos, os quais variaram de 45,7 a $94,5 \mathrm{mg} / \mathrm{L}$. Destaca-se também, os elevados valores do parâmetro cor para a maioria das amostras. 
Tabela 1: Parâmetros físico-químicos do efluente galvânico bruto

\begin{tabular}{|c|c|c|c|c|c|c|c|c|}
\hline Dia & Hora & $\begin{array}{c}\text { Cor } \\
(\mathrm{mgPt} / \mathrm{L})\end{array}$ & $\begin{array}{c}\text { Turbidez } \\
\text { (NTU) }\end{array}$ & $\begin{array}{c}\text { Condutividade } \\
\left(\mathrm{S} . \mathrm{m} / \mathrm{mm}^{2}\right)\end{array}$ & $\mathrm{pH}$ & $\begin{array}{c}\text { Ferro } \\
(\mathrm{mg} / \mathrm{L}) \\
\end{array}$ & $\begin{array}{c}\text { Zinco } \\
(\mathrm{mg} / \mathrm{L})\end{array}$ & Amostra \\
\hline \multirow{4}{*}{ 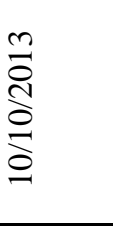 } & $13: 40$ & 55,6 & 17,98 & 123 & 1,7 & - & - & - \\
\hline & $15: 40$ & 99,5 & 48,3 & 5,74 & 5,8 & 6,95 & 45,7 & $\# 1$ e \#2 \\
\hline & $17: 40$ & 347,8 & 11,5 & 6,3 & 10,5 & - & - & - \\
\hline & $19: 40$ & 6,061 & 72,9 & 4,9 & 10,1 & - & - & - \\
\hline \multirow{6}{*}{ 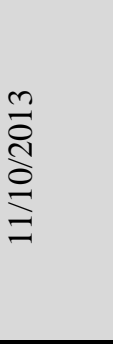 } & 07:30 & 33,3 & 25,8 & 24,5 & 1,5 & 75,9 & 69,1 & $\# 1$ 'e \#2' \\
\hline & 09:30 & 44,7 & 31,63 & 18,8 & 1,6 & 58,2 & 55,4 & - \\
\hline & 11:30 & 134,8 & 80,9 & 6,8 & 2,6 & 26,4 & 66,7 & \#3'e \#4' \\
\hline & $13: 40$ & 46,3 & 14,59 & 14 & 1,6 & 16,2 & 51,2 & - \\
\hline & $15: 40$ & 188,1 & 23,01 & 5,4 & 6,9 & - & - & - \\
\hline & $17: 40$ & 456,3 & 152,7 & 6,7 & 6,5 & 12 & 94,5 & \#5'e \#6' \\
\hline \multirow{6}{*}{ 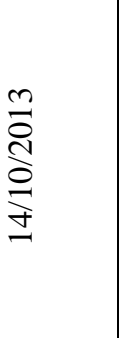 } & 07:30 & 127,4 & 83,9 & 6,9 & 2,7 & 28,6 & 48,1 & - \\
\hline & 09:40 & 1,68 & 120,1 & 5,6 & 10,3 & - & - & - \\
\hline & $11: 30$ & 141 & 87,7 & 13,5 & 12,8 & 23,9 & 66,7 & - \\
\hline & $13: 40$ & 328,5 & 6,82 & 3,5 & 10,3 & - & - & - \\
\hline & $15: 40$ & 8,229 & 98 & 6,9 & 2,7 & - & - & - \\
\hline & $17: 40$ & 423,3 & 96,5 & 4,1 & 4,6 & 14 & 60,8 & $\# 3$ e \#4 \\
\hline
\end{tabular}

\subsection{Tratamento do efluente bruto por precipitação química com cal hidratada}

Na Tabela 2 estão apresentados os resultados do tratamento por precipitação química empregando cal hidratada das amostras de efluente bruto selecionadas para os ensaios.

Tabela 2: Precipitação química empregando cal hidratada

\begin{tabular}{ccccccccccc}
\hline pH & $\begin{array}{c}\text { Fe } \\
\text { bruto } \\
\text { bruto }\end{array}$ & $\begin{array}{c}\text { Zn } \\
\text { bruto } \\
(\mathbf{m g} / \mathbf{L})\end{array}$ & $\begin{array}{c}\mathbf{p H} \\
\text { precipi- } \\
\text { tação }\end{array}$ & $\begin{array}{c}\text { Polímero } \\
(\mathbf{m g} / \mathbf{L})\end{array}$ & $\begin{array}{c}\text { Fe } \\
\text { tratado } \\
(\mathbf{m g} / \mathbf{L})\end{array}$ & $\begin{array}{c}\text { Eficiência } \\
\text { remoção } \\
\text { Fe (\%) }\end{array}$ & $\begin{array}{c}\text { Zn } \\
\text { Tratado } \\
(\mathbf{m g} / \mathbf{L})\end{array}$ & $\begin{array}{c}\text { Eficiência } \\
\text { remoção } \\
\text { Zn (\%) }\end{array}$ & $\begin{array}{c}\text { Lodo } \\
(\mathbf{g})\end{array}$ \\
\hline 1 & 5,8 & 6,95 & 45,8 & 8 & 20 & 0,444 & 93,6 & 2,704 & 94,1 & 0,026 \\
2 & 5,8 & 6,95 & 45,8 & 9 & 10 & 0,068 & 99,0 & 1,112 & 97,6 & 0,066 \\
3 & 4,6 & 14 & 60,8 & 9 & 15 & 0,972 & 93,1 & 1,176 & 98,1 & 0,052 \\
4 & 4,6 & 14 & 60,8 & 9 & 20 & 0,796 & 94,3 & 1,004 & 98,4 & 0,051 \\
\hline
\end{tabular}

Dos resultados das amostras \#1 e \#2, verifica-se que a precipitação química com cal hidratada em pH 9, mesmo em dosagem menor de polímero aniônico (floculante), ocasionou maior eficiência de remoção de ferro e zinco e maior quantidade de lodo gerado. Dos resultados das amostras \#3 e \#4, observa-se que mantendo o pH 9 e constante, a adição de maior quantidade de polímero aniônico como floculante, de 15 para $20 \mathrm{mg} / \mathrm{L}$, não influenciou significativamente na eficiência de remoção zinco e ferro e na quantidade de lodo gerado. 


\subsection{Tratamento do efluente bruto por precipitação química com soda barrilha}

$\mathrm{Na}$ Tabela 3 estão apresentados os resultados do tratamento por precipitação química empregando soda barrilha das amostras de efluente bruto selecionadas para os ensaios. Da mesma forma que para a cal hidratada, na precipitação química com soda barrilha, mantendo o pH constante, em 8 ou 9, uma dosagem maior de polímero aniônico (floculante) não ocasionou aumento significativo na eficiência de remoção dos metais e nem na quantidade de lodo gerada. Na maioria dos casos, houve redução na eficiência de remoção. A precipitação química com soda barrilha em pH 9 ocasionou maior eficiência de remoção dos metais zinco e ferro e menor quantidade de lodo gerada.

Tabela 3: Precipitação química empregando soda barrilha

\begin{tabular}{ccccccccccc}
\hline$\#$ & $\begin{array}{c}\mathbf{p H} \\
\text { bruto }\end{array}$ & $\begin{array}{c}\text { Fe } \\
\text { bruto } \\
(\mathbf{m g} / \mathbf{L})\end{array}$ & $\begin{array}{c}\mathbf{Z n} \\
\text { bruto } \\
(\mathbf{m g} / \mathbf{L})\end{array}$ & $\begin{array}{c}\mathbf{p H} \\
\text { precipi- } \\
\text { tação }\end{array}$ & $\begin{array}{c}\text { Polímero } \\
(\mathbf{m g} / \mathbf{L})\end{array}$ & $\begin{array}{c}\mathbf{F e} \\
\text { tratado } \\
(\mathbf{m g} / \mathbf{L})\end{array}$ & $\begin{array}{c}\text { Eficiência } \\
\text { remoção } \\
\text { Fe }(\mathbf{\%})\end{array}$ & $\begin{array}{c}\mathbf{Z n} \\
\text { tratado } \\
(\mathbf{m g} / \mathbf{L})\end{array}$ & $\begin{array}{c}\text { Eficiência } \\
\text { remoção } \\
\text { Zn }(\mathbf{\%})\end{array}$ & $\begin{array}{c}\text { Lodo } \\
(\mathbf{g})\end{array}$ \\
\hline $\mathbf{1}$ & $\mathbf{1 . 5}$ & 75.9 & 69.1 & 8 & 10 & 0.59 & 99.2 & 3.18 & 95.4 & 0.103 \\
$\mathbf{2}$ & $\mathbf{1 . 5}$ & 75.9 & 69.1 & 8 & 15 & 3.80 & 94.9 & 4.23 & 93.8 & 0.107 \\
$\mathbf{3}$, & $\mathbf{2 . 6}$ & 26.4 & 66.7 & 8 & 20 & 2.04 & 92.3 & 3.68 & 94.5 & 0.043 \\
$\mathbf{4}$ & $\mathbf{2 . 6}$ & 26.4 & 66.7 & 9 & 10 & 2.16 & 91.8 & 3.36 & 94.9 & 0.054 \\
$\mathbf{5}$, & $\mathbf{5 . 3}$ & 12 & 94.5 & 9 & 15 & 0.13 & 98.9 & 1.52 & 98.4 & 0.082 \\
$\mathbf{6}$ & $\mathbf{5 . 3}$ & 12 & 94.5 & 9 & 20 & 0.06 & 99.5 & 2.97 & 96.8 & 0.079 \\
\hline
\end{tabular}

Conforme análise visual realizada, a amostra $\# 1$ ' apresentou um decantado mais clarificado do que a amostra \#2', cuja turbidez foi visível. Além disso, as duas amostras apresentaram maior quantidade de lodo que as demais. As amostras \#3' e \#4' não apresentaram diferenças significativas entre elas no aspecto visual. A amostra \#6' também apresentou maior quantidade de precipitado que estas últimas.

\section{CONCLUSÃO}

Tanto a cal hidratada como a soda barrilha ocasionaram altas eficiências de remoção dos metais ferro e zinco, que variaram de 91,2 a 99,5\%. As maiores eficiências foram observadas para precipitação química em $\mathrm{pH}$ 9. Porém, $\mathrm{pH} 8$ já seria adequado para o tratamento, visando atendimento à legislação federal para lançamento de efluentes. Para ajustar o $\mathrm{pH}$, foram usadas maiores quantidades de soda barrilha do que cal hidratada. Um aumento na dosagem de polímero não aumentou significativamente a eficiência de remoção dos metais zinco e ferro e nem a quantidade de lodo gerado tanto para a soda barrilha como para a cal hidratada. Houve maior geração de lodo empregando a soda barrilha, o que pode ser vantajoso considerando a formação de carbonato de zinco, o qual poder ser utilizado como micronutriente de solo, porém é necessário realizar a caracterização do lodo para avaliar a quantidade presente deste composto.

Agradecimentos: Ao FAP/UNIVILLE e às empresas MG Óxidos e Galvânica Moderna. 


\section{REFERÊNCIAS}

ABNT - Associação Brasileira de Normas Técnicas. NBR-10004: Resíduos Sólidos Classificação. Rio de Janeiro: ABNT, 1987. 63p.

APHA. American Public Health Association. Standard methods for the examination of water and wastewater, $21^{\text {st }}$ ed. Washington, 2005.

BRAILE, P. M.; CAVALCANTI, J. E. W. A. Manual de Tratamento de Águas Residuárias Industriais. São Paulo: CETESB, 1993.

COLARES, C. J. G.; JÚNIOR, E. J. S.; COLARES, E. C. G.; COSTA, O. S. Estudo de caso do tratamento de efluentes líquidos gerados no processo de galvanoplastia. Anais do VIII Seminário de Iniciação Científica e V Jornada de Pesquisa e Pós-Graduação - Universidade Estadual de Goiás, 2010.

NASCIMENTO, M. M. G. S. Reuso dos efluentes gerados no tratamento superficial preliminar à pintura automotiva. Dissertação (mestrado). Programa de Engenharia Ambiental, Universidade Federal do Rio de Janeiro - UFRJ, Rio de Janeiro - RJ, 2012.

PEREIRA NETO, A.; BRETZ, J. S.; MAGALHÃES, F. S.; MANSUR, M. B.; ROCHA, S. D. F. Alternativas para o tratamento de efluentes da indústria galvânica. Engenharia Sanitária e Ambiental, v. 13, n.3, p. 263-270, 2008.

QUEIROZ, F. M. Caracterização eletroquímica, química e morfológica de aço "galvannealed" comercial. Dissertação (Mestrado). Tecnologia Nuclear - Materiais, IPEN/USP, 2003.

SILVA, A. F. M.; LIMA, I. O.; SILVA, J. A. G. Estação didática de tratamento de efluentes. Disponível em: <http://revistaeletronica.sp.senai.br/index.php/seer/article/viewFile/88/49>. Acesso em: 25 março 2014.

TOZE, S. Reuse of effluent water-benefits and risks. Agriculture and Water Management, v. 80, p. 147-149, 2005.

VALENZUELA, J. Tratamento de Efluentes em Indústrias Galvanotécnicas. Ed. Páginas e Letras: São Paulo, 126 p., 1999.

VAZ, L. G. L. Performance do processo de coagulação/floculação no tratamento do efluente gerado na galvanoplastia. Dissertação (Mestrado). Programa de Pós-graduação em Engenharia Química, Universidade do Oeste do Paraná - UNIOESTE, Toledo - PR, 2009. 